\title{
Key Success Factors of Software-Intensive Product Development
}

\author{
Mingtao Shi ${ }^{1}$ \\ ${ }^{1}$ bbw Hochschule / bbw University of Applied Science, Leibnizstrasse 11-13, Berlin, Germany \\ Correspondence: Mingtao Shi, bbw Hochschule / bbw University of Applied Science, Leibnizstrasse 11-13, \\ 10625 Berlin, Germany. E-mail: Consulting_Shi@yahoo.de
}

Received: April 11, 2013 Accepted: October 28, 2013 Online Published: December 8, 2013

doi:10.5539/cis.v7n1p58

URL: http://dx.doi.org/10.5539/cis.v7n1p58

\begin{abstract}
This paper revisits the key success factors of new product development by investigating a software-intensive product development project, which is presented in form of a detailed qualitative case study. The result reconfirms the existing wisdom that factors like top management sponsorship, presence of a heavy-weight project manager, close cross-functional collaboration and communication, skill routines and supporting tools used during the project execution as well as unambiguous and systematic product concept are essential enablers for the product development project to become a success. The case study has also revealed a number of additional aspects such as management competences in geographical coordination, complementary incentive system and contract management which, if managed insufficiently, may lead to unsatisfactory performance of the product development. Innovation managers in software industry may therefore pay attention to them, in order to improve the product development quality.
\end{abstract}

Keywords: product development, software-intensive product development, project management, innovation management, key success factors

\section{Introduction}

Product innovation is a crucial source for wealth creation at both firm and national levels. A nation's innovative performance depends significantly upon the creative capacity of its indigenous firms (Nelson, 1993). Once a country's innovation-driven markets are shaped by local firms, these firms are able to not only generate dynamic growth rates for themselves, but also greatly increase the national wealth. Striking cases abound, such as Apple and Samsung as the two dominating mobile phone vendors originated from the United States and South Korea respectively, Germany's IT giant SAP, Cisco and Huawei as the global producers for telecommunications equipment which stem from the United States and China respectively. These industries have created unprecedented value for nations and customers and these nations are either persistently affluent societies or transitional economies experiencing lasting growth. There is little doubt about the fact that successful innovative firms are one of the most important factors creating micro- and macroeconomic wealth.

While all firms mentioned above are obviously operating in different ways because of their different technical, managerial and cultural origins, they do share one fundamental characteristic. Successful innovation-driven firms always endeavour to create innovative products and strive for excellence in product development. Fostering new products is at the heart of these firms' strategy to obtain sustained competitive advantage. Product innovation entails improving existing product spectrum as well as nurturing and growing quantitative or qualitative novelty. In his seminal work, Christensen and Bower (2009) warn rightly that established industry incumbents may perceive high barriers to embark on disruptive technologies. Successful firms fully understand the implications of this argument and constantly capitalise on architectural and radical technological innovations.

There have been many studies examining the key success factors of new product development. Some recent publications provide a condensed summary as follows (Tidd \& Bessant, 2009; Schilling, 2013):

- product advantage: product superiority and differentiating advantages vis-à-vis competing products, high performance-to-cost ratio and value perceived by the customers;

- Market knowledge: predevelopment preparation including initial screening, preliminary market assessment, preliminary technical appraisal, detailed market studies, business as well as financial analysis; 
- Product concept and design: clear definition of target markets, product concept, benefits to be delivered, clear positioning strategy of the product, a list of product requirements, features and attributes;

- Risk analysis: market-based, technological, manufacturing and design sources of risk to the development project must be assessed and plans made to address them;

- Organisational effectiveness: involvement of internal cross-functional teams and external customers, users and suppliers;

- Project resources: availability and allocation of sufficient financial and material resources, and human skills;

- Project execution: quality of technological and manufacturing activities, and all pre-commercialisation business analyses and test marketing;

- Heavyweight teams and seniority of project manager: development of architectural products often require fulltime team members recruited from functional departments and project managers are typically senior managers possessing significant authorities (also see Clark and Wheelwright, 2009);

- Top management support.

Today, innovative products are often systems consisting of developed software, manufactured hardware and natural materials such as rare earth elements. Natural materials are controlled by a handful countries owning them. Price or quantity fluctuations of natural resources may impact a product's margin significantly. Manufactured hardware provides the physical and architectural form of the product and is also the carrier of software components. The capabilities of the hardware have been improving at exponential rate as the description provided by Moore's law. Hardware modules used in a variety of industries are usually commonly available in the competitive global marketplace and continue to be strongly standardised. The production of the hardware has thus achieved greater and greater scale economies over time. On the contrary, although software development environments and programming frameworks may follow certain technological trajectories, the design, implementation and production processes of the software can hardly be standardised. Notably, innovative systems have become increasingly software-intensive and the role the software plays during the product development has become increasingly predominant in recent years. However, published contributions explicitly treating software-intensive product development from the perspective of innovation management have been relatively rare. Studies investigating the success factors of software-intensive innovation therefore can also deepen the understanding of more general product development.

\section{The Study}

This paper harnesses an in-depth qualitative case study to examine a software-intensive product development project. The result of the investigation is used to revisit and challenge the traditional wisdom about the concept of the successful product development. The exploration of new and confirmation of existing success factors of product development can be a valuable contribution for the advancement in theory and for the practitioners in the field.

When used properly, the qualitative methodology is an effective way to conduct managerial studies, especially for exploratory investigations (see e.g. Yin, 2008; Saunders et al., 1997). Observation is often employed in the qualitative primary research. There are mainly two kinds of observation, which are the non-participant and participant observation (Gill \& Johnson, 1997). Information and analysis of the author's project experience provided in this paper may be perceived as a form of the participant observation, where the author acted as a line manager during the project conduction, accounting for the requirements engineering in IT area, and was also one of the two project leaders responsible for the project personnel and overall performance of the product development. Some of the project description certainly also stems from secondary sources such as documents, protocols and meeting minutes.

The case study deals with a product development project in the banking industry. The names of the participating firms are kept anonymous deliberately because of the non-disclosure settlements agreed among the project actors. The major objective of the project was to conceptualise, design, develop and introduce software-intensive systems that provide features of financial products.

\section{Software-Intensive Development}

Several common characteristics can be found in almost all software-intensive engineering projects that are well managed. Firstly, software-intensive development follows a process pattern such as the waterfall or prototyping model (see e.g. Pressman, 2010; Haberfellner et al., 2012). In recent years, agile models such as Scrum and 
Kanban have emerged and become highly coveted by the industrial firms (Anderson, 2011; Balzert, 2008). Agile models are primarily created and used to increase the overall efficiency in the software-intensive development.

Secondly, constructing software-intensive products requires the following major task elements:

Table 1. Major task elements in software-intensive development

\begin{tabular}{|c|c|c|}
\hline Task elements & Description & Work products \\
\hline $\begin{array}{l}\text { Comprehending } \\
\text { the requirements }\end{array}$ & $\begin{array}{l}\text { The development team must understand what the } \\
\text { explicit and implicit needs of the customers are. } \\
\text { Nota benne, customers are not the only } \\
\text { stakeholders during the development work. There } \\
\text { are also other internal or external interest groups } \\
\text { that intend to influence the scope and process of } \\
\text { the product development. The requirements are } \\
\text { elicited, analysed, modelled, negotiated by the } \\
\text { participating stakeholder and finally validated. }\end{array}$ & $\begin{array}{l}\text { The typical work results are a number } \\
\text { of documented system specifications. }\end{array}$ \\
\hline $\begin{array}{l}\text { Designing the } \\
\text { system }\end{array}$ & $\begin{array}{l}\text { In accordance with the requirements, the } \\
\text { development team must create models that } \\
\text { provide technical details about the product } \\
\text { architecture, components and their interfaces with } \\
\text { each other and to the external technical instances. }\end{array}$ & $\begin{array}{l}\text { The work products are usually a set of } \\
\text { design documents defining the } \\
\text { strategies and tactics of the product } \\
\text { construction. }\end{array}$ \\
\hline $\begin{array}{l}\text { Implementing and } \\
\text { testing the } \\
\text { product }\end{array}$ & $\begin{array}{l}\text { Constructing the designed system normally } \\
\text { encompasses software coding and software } \\
\text { integration on hardware platforms. Cooperation } \\
\text { with hardware team might become necessary here, } \\
\text { in order to, for example, make laboratory samples } \\
\text { available for early coding and preliminary testing, } \\
\text { and, to define material list more precisely for later } \\
\text { procurement. Testing activities are conducted } \\
\text { when the prototype, the product or a part of the } \\
\text { product has been accomplished, scrutinising the } \\
\text { compliances of the developed product with the } \\
\text { design and requirements details. }\end{array}$ & $\begin{array}{l}\text { The work typically includes the } \\
\text { availability of the preliminary and test } \\
\text { systems and a set of documented test } \\
\text { plans, test procedures, test cases and } \\
\text { test result reports. Implementation and } \\
\text { testing take place in an iterative } \\
\text { manner. }\end{array}$ \\
\hline $\begin{array}{l}\text { Managing build, } \\
\text { release and } \\
\text { deployment }\end{array}$ & $\begin{array}{l}\text { Software codes of the product are translated into } \\
\text { machine or machine-like files and reconciled for } \\
\text { customer usage. Rules for software updates and } \\
\text { product upgrades are determined. Managers and } \\
\text { engineers also need to contemplate how to deliver } \\
\text { the developed product and how the customer can } \\
\text { smoothly apply the product at the operational site. }\end{array}$ & $\begin{array}{l}\text { The work products are usually } \\
\text { installation files made available in a } \\
\text { Release Management System and, } \\
\text { packaged and preconfigured systems } \\
\text { ready for delivery. Other relevant } \\
\text { tasks include the organisation of } \\
\text { logistics, installation and user training } \\
\text { routines. }\end{array}$ \\
\hline
\end{tabular}

Thirdly, product technologies, especially the software-intensive systems, are increasingly planed and developed within supporting software tools. Requirements, design and testing concepts evolve gradually but dynamically, necessitating the utilisation of version and change management tools.

Fourthly, in order to improve future performance, software-engineering firms or firms with software R\&D are usually motivated to assess the degree of success after the project completion. Meredith (2009) argues that a project should be managed and evaluated from four angles: scope, time, budget and resource as it is shown in the following figure. 




Figure 1. Criteria for evaluating success of product development projects

\section{Case Study: Introducing Software-Intensive Systems for Financial Services}

While providing the project description, the case study intends to focus upon the aspects that mattered importantly to the success factors of software-intensive development. This section first gives an overview of the project scope, stating what, for whom and why the product was to be conceptualised and developed. The author elaborates further on the case study, by describing and commenting a number of project aspects, which are considered as the significant issues that influenced, directly or indirectly, the final project outcomes. The degree of the project success is then evaluated. Based upon the analysis in this section, the conclusion is drawn in the next section, when the author summarises the lessons learnt and establishes the linkage between the empirical results of the case study with the arguments put forward by the literature.

\subsection{Project Scope}

Industrial firms today rely heavily upon software applications to support their value chain activities. While only few software vendors are producing the core software systems, most firms are primarily interested in the applications of core systems. Although core systems are usually rich in data libraries and logical-mathematical mechanisms, they are seldom tailored to the business needs of the individual firms applying them. Core systems thus must be parameterised and customised to flexibly fit the different industrial contexts. This is the background why the development project described in this section has emerged.

The firm that has initiated the software-intensive product development is the headquarters of an international network consisting of approximately a dozen of banks and consulting units specialised in financial services. These financial institutions are located predominantly in Central Asia, Africa and South America. The headquarters located in Germany partially or wholly owns the operating units of the network on the one hand, and, trains and sends management teams to the banks and institutions on the other. Furthermore, before the product development commenced, the headquarters had developed and provided own software-intensive systems to its regional subsidiaries. As the business range and consumer coverage grew markedly over the past decade, the existing proprietary systems became a major bottleneck for the product diversity and geographical consumer coverage. The decision makers at the headquarters quickly decided to embark on proven technologies that can benefit its international businesses on the long-term run. Thus, the product development mainly focused upon using the functionalities made available by a core banking system from SAP to precisely build banking and credit products marketed to the customers by the businesses operating in different regions and countries.

\subsection{Senior Management Support and Heavyweight Project Leaders}

Compared with the previously used house-made systems, the purchased core system is designed and coded entirely differently. Although the core concepts of the financial products would not change, how the features and functionalities existing in the new core system could be aligned and linked together to enable operative financial services was certainly an endeavour that was in essence an architectural innovation. With so many unknown factors and uncertainties, it was clear to the top management at the headquarters that this product development project would become something completely new to the R\&D staff in the IT area. However, what was also clear for the top management was that, in favour of the strategic prosperity of the businesses, the change from the legacy to new system was inevitable.

By appointing two senior managerial members in the IT area with personnel authority to jointly take over the responsibility of the development project, the top management mobilised the headquarters' internal R\&D capacity for the realisation of the project objective. The project leaders decided to adopt the waterfall model as a 
more traditional approach, in order to manage the project status. Microsoft Project and Office were used to build and apply project monitoring and execution instruments such as budget plan, price calculation, milestone plan, work breakdown packages and manpower allocation. The group of developers additionally used the Kanban-board to trace the advancement of the work packages and their associated tasks till these are either completed or discarded. Besides the project leaders, the top management also exerted subtle control over the project progress, by attending periodical work package review sessions, demanding monthly progress reports from the project team and stimulating discussions about the possible technical solutions to risk management issues such as operational fraud, personnel security and data backup in daily banking practice.

\subsection{Development Process}

The project team decided to commence the development work by studying how the core system generally would behave to portray the financial products. The consultants supplied by the core system vendor supported this activity by carrying out recurring on-site training sessions with the project leaders and other project team members. Subsequently, the requirements engineers and software developers in the development team conducted in-depth interviews with the financial experts at the headquarters and in the local banks, aiming at comprehending the complex structure of financial products. In the area of credit business, relevant knowledge included debt and collateral management, repayment planning and risk management. Also in the area of retail banking, knowhow in a number of categories, such as customer account management, current account management (cheques, standing orders, money transfer), savings and deposits management and card management (debit and credit cards), seemed to be indispensable for the product development. While discussing the product functionalities, the development team has also obtained sufficient related auxiliary knowledge in financial accounting, encompassing risk and treasury management, liquidity planning, internal and external reporting management. Through the learning processes, the acquired knowledge has greatly helped the engineers in the development team understand, digest and model the requirements.

The following diagram shows the structure of an activity diagram used by the engineers as the project team analysed the elicited knowledge. Mapping actors and roles, their tasks and their work products step by step in the banking or credit processes turned out to be essential for the developers to design the possible solution variations, which in turn formed the basis for the subsequent parameterisation and customisation work as the features in the core system were selected and combined, and rules and parameters were carefully set. For a same financial service, banks and financial institutions in the network may have received different product variations that were configured and parameterised differently because of country-specific or bank-unique factors such as preferred interest rates and repayment period length, regulatory circumstances and the organisation of the business processes. As the software products tailored to the individual needs of the banks were completed, developers and hardware experts at the headquarters collaborated intensively to realise the integration of the software systems on web-, application- and database-servers with backup and security capabilities.

\subsection{Adapted Incentive System}

During the period of requirements elicitation and modelling, it became clear that the product owners of the local banks were undoubtedly most familiar with the individual features and parameters of the products offered to the local customers. Parameters such as interest rates, penalty rates and repayment period of disbursed credit were subject to local regulatory bodies and country-specific policies. Meanwhile, local institutions, however, generally lacked of knowledge in software-intensive product development. Business journeys were therefore necessary for the development team at the headquarters to establish direct contact with local staff. An intriguing phenomenon observed in this context was that high-qualified engineers and developers were rather reluctant to travel to countries, where infrastructure has been much less developed and the personal security insufficiently protected. Project leaders negotiated with top management for receiving additional budgets and designed a reward system to encourage project members to travel and absorb country-specific local knowledge more efficiently. This system consisted of a number of motivating components. By evaluating the tasks to be carried out carefully, the project leaders and the engineers strived for a shorter stay and decided jointly on the number of travelling days. Development team members were travelling in pairs, so that each individual felt and travelled safer. Except the usual allowance for the business trips, additional financial incentives were provided for each flight to a country beyond the borders of European Union. Project leaders also defined financial rewards for each project member when the project should be accomplished earlier than scheduled. The point here is that complementary incentive systems adapted to individual projects and in addition to the usual reward and salary structure may be generally necessary in many new product development projects. 


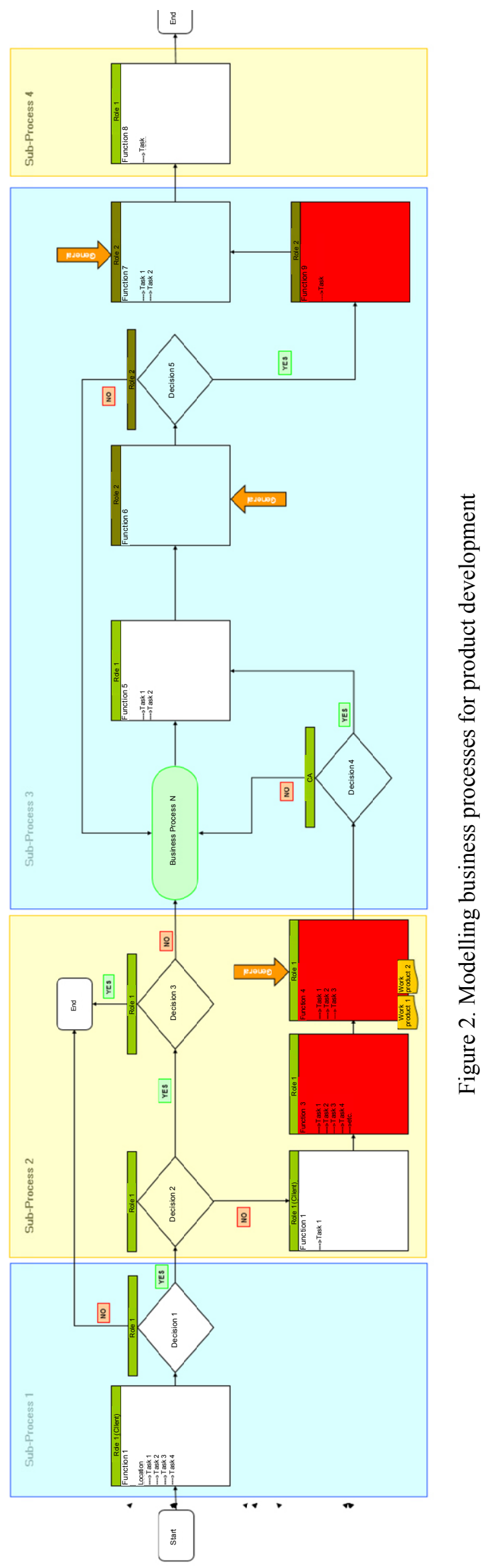




\subsection{Geographical Dispersion}

Another issue observed during the project realisation was the high intensity of necessary project coordination caused by the geographical dispersion of the participating actors. While the software-intensive product development was, as stated above, initiated by the firm specialised in the financial services with the headquarters in Germany, the consultants transmitting the knowledge about how to use the core system were located in Britain. The core system itself however has been developed and built in India. The development team in Germany therefore also had to communicate with the coding teams in India from time to time, especially during the final parameterisation and customisation in the core system, in order to clarify detailed technical issues and, if necessary, demand assistance to eliminate bugs. The delivered products became deployed in an international network encompassing operating countries in Central Asia, Africa and South America. These coordination activities turned out be time-consuming and absorbed significant manpower, especially during the requirements elicitation and system go-live.

\subsection{Technological Supporting Tools}

During the project realisation, the product development activities also required effective technology support. Prior to this project, technical development at the headquarters had relied primarily upon textual specifications composed and edited in the Microsoft Office programmes. This kind of practice had made change and version management rather overly difficult when complex products were to be conceptualised and implemented. As the work packages of the product development project have unfolded, budgets were made available for the investments and new information systems enabling the modelling and management of the requirements and technical design were introduced. Furthermore, international and local teams also used communications tools such as Messenger, Skype as well as web-meeting and web-seminar tools intensively to support coordinative activities. Through these technologies development work related to the requirements and design could be carried out in distinctly separate areas and clusters of the supporting systems, which in turn brought about a more effective managerial environment for technical specifications. Furthermore, also the implementation tasks could be documented and the progress status be logged on a daily basis. In addition, criteria for testing developed features and functions were linked to the specifications of the requirements and to the implementation documentation in the new information systems. Notably, the introduction of the new supporting technology has evolved the organisational processes in product development to follow the logic of the standardised approaches built in the supporting tools and thus have become more effective and efficient.

\subsection{Contract Management}

On the one hand, a supply contract was signed with the upstream vendor of the core system. Because the core system to be delivered was a highly complex system, the top management insisted on a written and signed List of Delivery, which explicitly listed all deliverables of the contractual parties. The list encompassed not only the hardware, software and spare parts, but also the documentation related to system test procedures and logistics management. Services relevant to the installation, maintenance and training were regulated in a separate service contract. On the other hand, supply contracts were agreed among the headquarters and the downstream financial institutions that shall use the customised systems. Prior to the development start, the project leaders defined the milestones to indicate significant events that should take place during the project realisation and when they should occur. The milestones clearly defined, for example, when the customised systems were to be delivered and integration test should commence. The milestones agreed with the banks were signed and seen as a part of the contract. Furthermore, technical specifications stating duties and obligations during development and system integration also became a part of the contract. The headquarters firm has also contracted a number of the subcontractors in the respective operating countries for update and maintenance services of the customised systems. The experience gained from this project convincingly shows that the contract management impacts the quality of the product development considerably. For example, prices would influence the budget planning of the product development and, delivery date and milestones would directly affect how the development is actually organised and resources are allocated. Key parameters of a contract such as prices, milestones, delivery content, warranty and post-delivery services can determine, to a large extent, the circumstances, under which the product development project is actually organised, executed and supported.

\subsection{Project Evaluation}

Like the evaluation of many other technical development projects, the result of the project described in this paper was rather a double-edged sword. Certainly, there were aspects observed and documented that characterise successful projects. The delivered products were able to model the operative businesses in the banks. Based upon the elicited product information, the developers tailored the core system to the needs of the local content 
effectively. The feedback from the local institutions and their reports concerning the reaction of the consumers and business customers confirmed that the customised and parameterised applications were well defined and developed.

When the time of project realisation is evaluated, it must be said that this development project was rather less successful. The software-intensive product was delivered with significant delay. The initial schedule foresaw approximately 12 months as the maximal time needed to cover all the project activities. However, it took the development team about 30 months before the banking products were introduced and deployed in banks and financial institutions. The budget and resource objectives suffered badly from the lengthy project execution time. Commercial and technical personnel involved in the project has swallowed considerable financial budgets. Especially the monetary resources allocated to the core development team at the headquarters became enormous due to the salary level of high-qualified manpower in a high-income European country and additional incentive programmes. Because a significant portion of the headquarters' $R \& D$ capacity was fulltime occupied by this project, other parallel higher-priority projects achieved only insufficient progress and support.

\section{Conclusion}

A number of factors observed in the case project provide solid basis to explain why the software-intensive product development was successful as far as the product scope is concerned. Firstly, without the strong symbolism and tangible support from the top management and the heavy-weight project leaders, the project would not be able to have gained so much moral respect, grasped abundant financial and manpower budgets that helped the product development gather momentum quickly, and retained the human resources durably. Secondly, the necessary collaboration among the internal and external functional teams, especial the knowhow transfer from the commercial to the technical teams makes it evident that technical product development is inherently multidisciplinary. Thirdly, the development process of the project showed that the commercial and technical teams developed skill routines and applied technological tools to better manage their respective disciplinary subjects and communicate with each other. A project is gradually realised, when such technological and managerial activities are performed. Proficient knowledge and experience in project execution is therefore positively correlated to the product development performance. Fourthly, replying upon the technological tools in the fields of requirements engineering, design engineering, implementation and testing, technicians and managers of the project team nurtured and defined unambiguous and systematic product specifications and potential risks, from which the detailed work tasks then result. Fifthly, the described development project received great acceptance and support, because employees and managers recognised the technical product advantage the development may achieve. Concentrating on parameterisation and customisation on the platform of a core system with vast libraries was a product strategy that would undoubtedly refine the quality of the future product conceptualisation and significantly shorten the time-to-market of the new or improved financial products. So far, the experience gained from this project is largely consistent with some of the traditional arguments.

The project experience has nonetheless also taught lessons from which the unsatisfactory results of the project may stem. Geographical coordination, adapted incentive system and contract management are insights gained by the case study that are hardly treated by the existing literature. Product development environment has increasingly become not only multinational but also multicultural. It is likely that future product development will generally require high-level management competences in geographical coordination. Without intra- and inter-organisational business rules as well as the support of information and communications technologies, the project expenditure for time and other resources will likely exceed the threshold of pain for many innovative firms. The case study has further indicated that a complementary incentive system may be generally beneficial to raise the motivation and thus reduce the overall costs of product development projects. The necessity of incentive adaptation can be caused not only by the needs for business travel but also by other project-specific reasons. Finally, the contract management had played a crucial role during the project initiation and realisation. In a product development project, contracts may comprise arrangements with multiple partners, such as suppliers, product users and possibly with subcontractors. The negotiated rules typically cover price conditions, milestones events and their delivery time, product or delivery content, and service agreements. All these issues cause great impact on the product planning and project efficiency. Although these aspects are revealed through a software-intensive project, they may be tested and verified in further empirical studies investigating the more general product development. 


\section{References}

Anderson, D. J. (2011). Kanban: Evolutionäres Change Management für IT-Organisation. dpunkt.verlag, Heidelberg.

Balzert, H. (2008). Softwaremanagement, 2, Auflage. Spektrum Akademischer Verlag, Heidelberg.

Christensen, C. M., \& Bower, J. L. (2009). Customer Power, Strategic Investment, and the Failure of Leading Firms. In R. A. Burgelman, C. M. Christensen \& S. C. Wheelwright (Eds.), Strategic Management of Technology and Innovation (5th ed., pp. 330-350). New York: McGraw-Hill/Irwin.

Clark, K. B., \& Wheelwright, S. C. (2009). Organizing and Leading "Heavyweight" Development Teams. In R. A. Burgelman, C. M. Christensen \& S. C. Wheelwright (Eds.), Strategic Management of Technology and Innovation (5th ed., pp. 1053-1064). New York: McGraw-Hill/Irwin.

Gill, J., \& Johnson, P. (1997). Research for managers. London: Paul Chapman Publishing.

Haberfellner, R., Fricke, E., Weck, O., \& de Vösser, S. (2012). Systems Engineering, 12, Auflage. Orell Füssli Verlag, Zürich.

Meredith, M. J., \& Mantel, S. J. (2009). Project Management: A Managerial Approach (7th Ed.). Hoboken, N.J.: John Wiley \& Sons.

Nelson, R. (1993). A Retrospective. In R. Nelson (Ed.), National Innovation Systems: A Comparative Analysis (pp. 505-523). New York: Oxford University Press.

Pressman, R. S. (2010). Software Engineering: A Practitioner's Approach (7th Ed.). New York: McGraw-Hill Companies Inc.

Saunder, M., Lewis, P., \& Thornhill, A. (1997). Research methods for business students. London: Pitman Publishing.

Schilling, M. (2013). Strategic Management of Technological Innovation (5th Ed.). New York: McGraw-Hill Education.

Tidd, J., \& Bessant, J. (2009). Managing Innovation: Integrating Technological, Market and Organizational Change (4th Ed.). Chichester, West Sussex: John Wiley \& Sons Ltd.

Yin, R. K. (2008). Case Study $R$ esearch: Design and Methods (4th Ed.). Thousand Oaks, C.A.: Sage Publications.

\section{Copyrights}

Copyright for this article is retained by the author(s), with first publication rights granted to the journal.

This is an open-access article distributed under the terms and conditions of the Creative Commons Attribution license (http://creativecommons.org/licenses/by/3.0/). 